\title{
A Comparative Analysis for a Flux-Modulated Permanent-Magnet Motor with an Improved Structure
}

\author{
Zhongfeng Zuo ${ }^{1, ~ a ~}$, Huijuan Liü ${ }^{2, b}$, XiangZhao,HaiJiao Zhang, YiDuan Chen ${ }^{3, c}$ \\ ${ }^{1,2,3}$ School of Electrical Engineering, Beijing Jiaotong University, Beijing, 100044, China \\ azhongfengdazuo@126.com, bhuijuanliu@bjtu.edu.cn
}

Keywords: flux-modulated (FM), conduction iron segments, low speed drive, finite element method (FEM), permanent magnet motor

\begin{abstract}
This paper introduces a flux-modulated (FM) permanent magnet motor with an improved structure. The conduction iron segments which plays flux-modulated role exist in the air gap between rotor and stator for the original FM motor. But by artfully integrating the any number of flux-modulated iron teeth which can adjust space harmonic of the air-gap magnetic field in every stator pole, the novel motor can readily achieve the high torque output at low speed. And then by using the time-stepping finite-element method (FEM), the basic characteristics, cogging torque, torque angle and core loss are analyzed. The theoretical analysis and simulation results show that the proposed motor can not only retain the advantages of original motor, but also have other merits.
\end{abstract}

\section{Introduction}

In order to reduce the emissions of vehicle exhaust and the use of fossil fuels, the development of EV becomes more and more necessary. As is known, the study of high-performance drive system plays a key role in EV's development. A mechanical gear-box is usually used to reduce the motor speed to make it compatible with the load characteristics. But the use of mechanical gears will inevitably reduce the energy transmission efficiency.

Recently, magnetic gears are proposed to replace the mechanical ones. The magnetic gears have a very competitive torque transmission efficiency compared with their mechanical counterparts. Magnetic gears inside the motor act as two rotation rotors, through the middle of the magnetic flux-modulated iron segments change the output speed [1,2]. Yet this kind of motor have three air gaps and two rotating parts, make its mechanical structure more complicated, increased the manufacturing of difficulties and cost. Reference [3,4] proposed another design, it simplified this complexity. The high speed rotating magnetic field is generated by the armature windings of stator, its stationary iron segments made of silicon steel laminations can modulate the air gap field space harmonics, then rotor rotate at a low speed efficiently. But it still has two air gaps, one on either side of the stationary iron segments and this will result in installation difficulties, at the same time, the life of motor decreases.

This paper proposes another improved scheme, that the conduction iron segments are directly coupled into the stator forming a series of salient teeth to adjust air-gap magnetic field space harmonic. This structure has higher mechanical robustness [5,6].

Models of the original motor (called motor I) and the new motor (called motor II) are established using transient finite element analysis method to analyze the Back EMF and its harmonic analysis, maximum output torque, core loss and maximum power angle. The theoretical analysis and simulation results show that the proposed motor is feasible. Moreover, its deep trench structure improves the ability of speed adjusting with field weakening.

\section{Simulation Results and Analysis}

The prototypes and principle

The intersection structure diagrams of motors are shown in Fig.1, (a) for the motor I, (b) for the motor II. Their main dimensions are listed in Table I. 


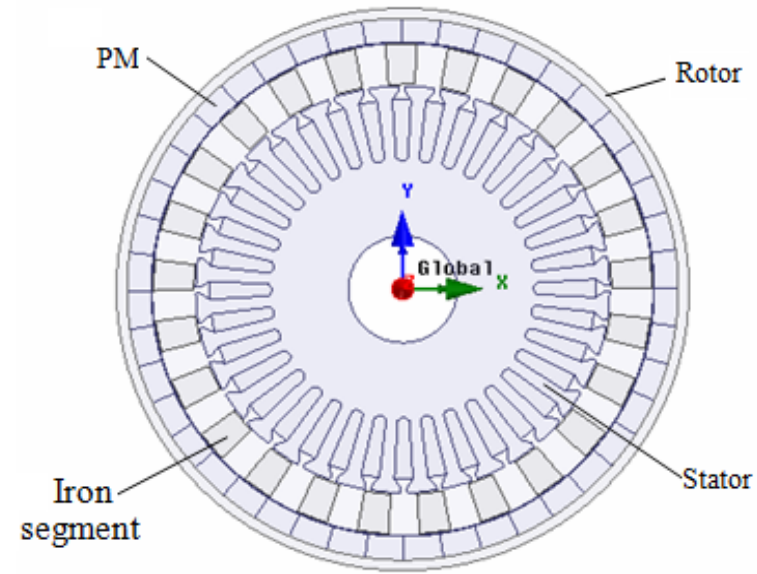

(b)

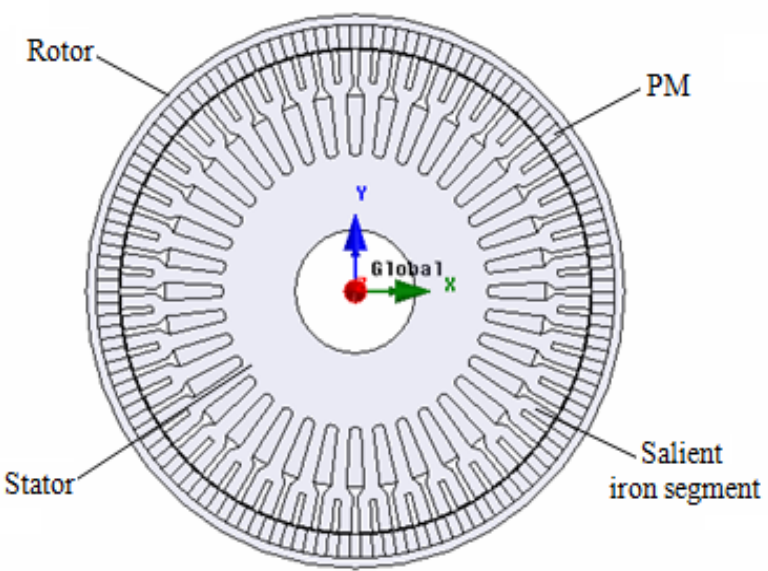

(a)

Fig.1. Overview of an intersection structure of motor. (a) for the motor I ,(b) for the motor II

TABLE I. The parameters of the motors

$\begin{array}{ccc}\text { Parameters } & \text { Motor I } & \text { Motor II } \\ \text { Frequency } & 220[\mathrm{HZ}] & 22[\mathrm{HZ}] \\ \text { Axial length } & 44[\mathrm{~mm}] & 44[\mathrm{~mm}] \\ \text { Outside radius of outer rotor } & 92[\mathrm{~mm}] & 92[\mathrm{~mm}] \\ \text { Outside radius of gear PM } & 88.6[\mathrm{~mm}] & 88.6[\mathrm{~mm}] \\ \text { Inside radius of gear PM } & 80.8[\mathrm{~mm}] & 80.8[\mathrm{~mm}] \\ \text { Outside radius of stationary ring /salient iron segments } & 80.2[\mathrm{~mm}] & 80.2[\mathrm{~mm}] \\ \text { Inside radius of stationary ring } & 67.2[\mathrm{~mm}] & \text { Non } \\ \text { Outside radius of stator } & 66.6[\mathrm{~mm}] & 66.6[\mathrm{~mm}] \\ \text { Inside radius of stator } & 17.5[\mathrm{~mm}] & 17.5[\mathrm{~mm}] \\ \text { Number of outer rotor pole pairs } & 22 & 69 \\ \text { Number of stationary iron pieces/ salient iron segments } & 25 & 72 \\ \text { Number of stator pole pairs } & 3 & 3\end{array}$

For the sake of simple performance comparison, the excitation currents in the motor windings are assumed to be sinusoidal at a frequency of $220 \mathrm{HZ}$. The synchronous speed both are $4400 \mathrm{rpm}$. The two motors have the same outer diameter and axial length, exactly the same material type and amount of the permanent magnet, the stator has a integer slot distribution winding. According to [1], the gear ratio of the motor is:

$$
\begin{aligned}
& G_{\mathrm{r}}=\left(P_{\text {stator }}-N_{\text {iron }}\right) / P_{\text {stator }} \\
& N_{\text {iron }}-P_{\text {stator }}=P_{\text {rotor }}
\end{aligned}
$$

Where $P_{\text {stator }}$ is the number of stator pole pairs, $P_{\text {rotor }}$ is the number of rotor pole pairs and $N_{\text {iron }}$ is the number of stationary iron pieces or salient iron teeth. $G_{\mathrm{r}}$ is the gear ratio of the motor.

Therefore the output speed is:

Speed $_{1}=4400 * 3 / 22=600 \mathrm{rpm}$

Speed $_{2}=4400 * 3 / 69=191 \mathrm{rpm}$

\section{Finite-element Analysis Results}

\section{Cogging Torque}

Cogging torque is one of those pulsating torque appearing in permanent magnet machines, and the cogging torque ripple usually results in vibration and acoustic noises, especially at low speeds and under light loading. 
The stator winding current excitation is set to 0 , the rotor rotate at $1 \mathrm{deg} / \mathrm{s}$ when using FEM. The cogging torque curve versus rotor position is shown in Fig. 4.

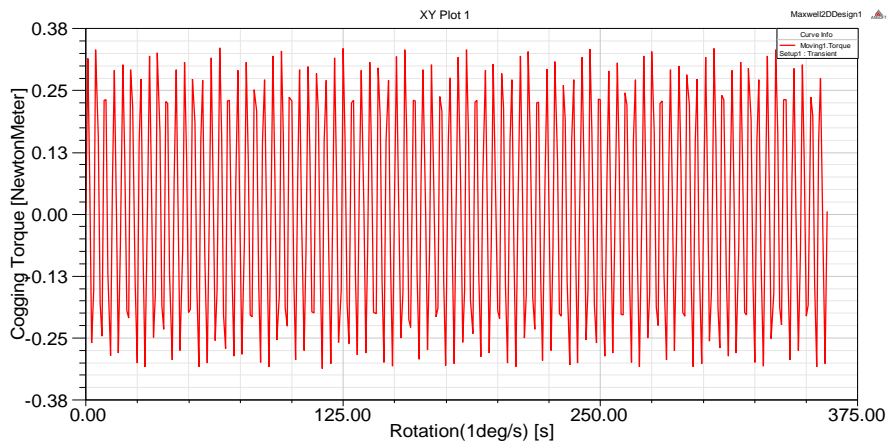

(a)

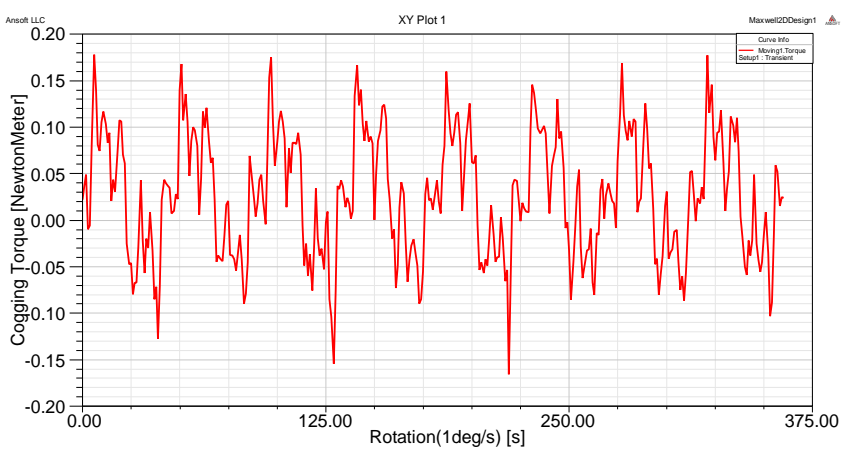

(b)

Fig.4.The cogging torque curve versus rotor position

We can know that the cogging torque of motor II is smaller. This is because that the combination of pole pair number and slot number is similar to that of a fractional- slot motor.

\section{Torque Angle}

The more complex the structure of the motor, electromagnetic relationship the more likely it fails to comply with a fixed relationship, it is only through computer simulation or experiments to find the electromagnetic relationship.

Using FEM, the curve of the torque versus initial angle of rotor is found out, such as Fig 5.

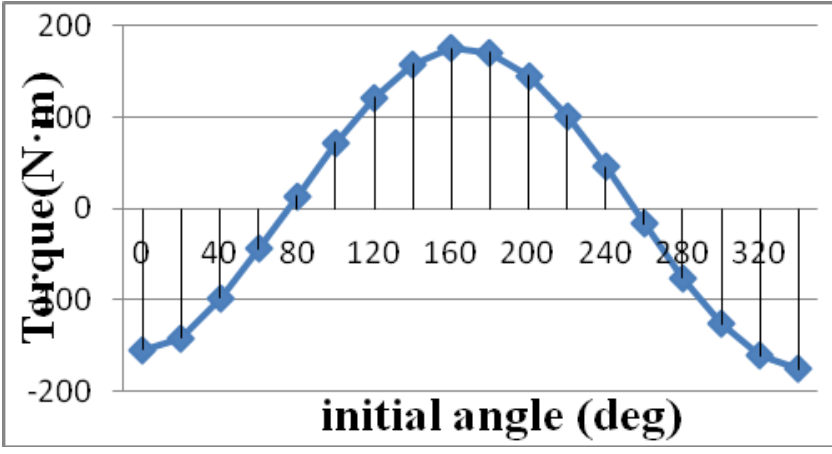

(a)

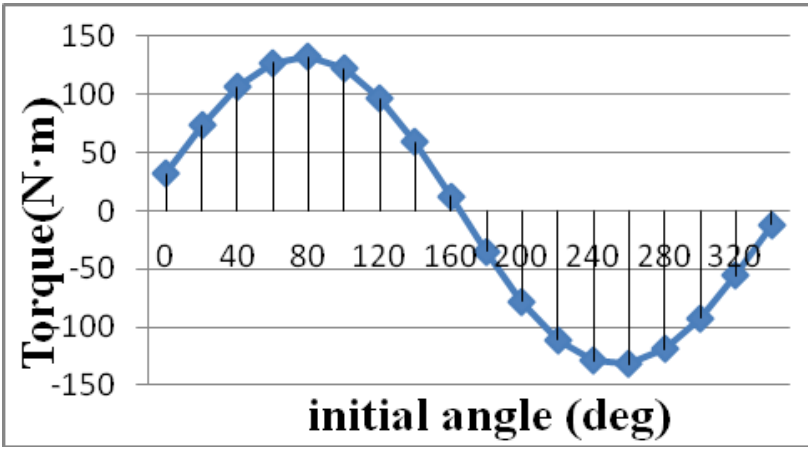

(b)

Fig.5. Simulation result showing the Torque curve versus Rotor initial position, (a) for the motor I, (b) for the motor II

According Fig 5, when the initial phase angle of the AC current is in the vicinity of 160 degrees, motor I have maximum torque. For the motor II, the angle is 80 degrees. Although the maximum output torque of the motor II is small than motor I, but the motor II can start up at a lower speed, its torque and speed ratio is better.

\section{Core loss}

The core losses of the two motors are computed by using the FEM presented in Fig.7 and the results showed that the core loss of these two motors is almost the same.

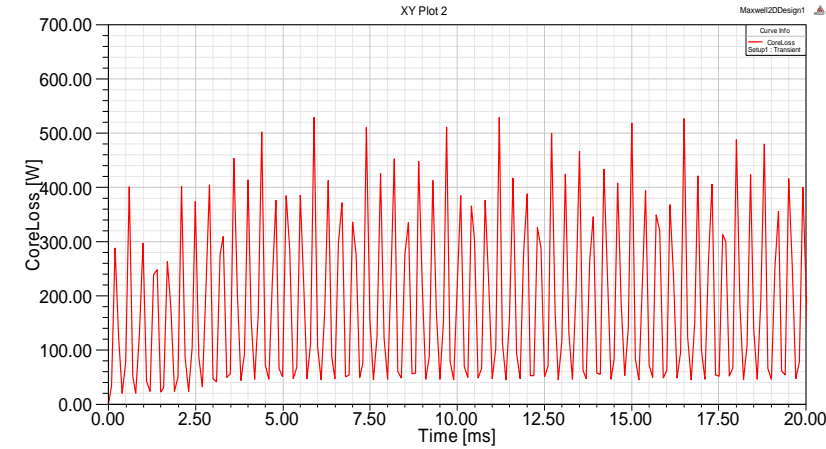

(a)

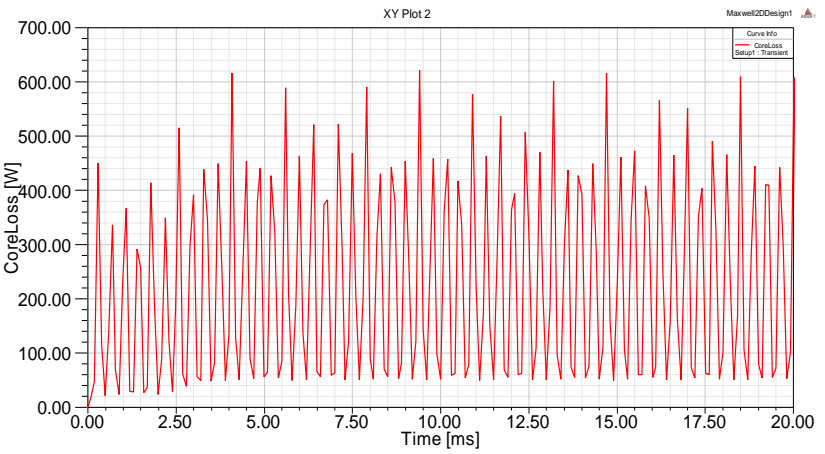

(b)

Fig.7. Core loss curve, (a) for the motor I, (b) for the motor II 


\section{Conclusion}

This paper focuses on the simulation performance of the original flux-modulated PM motor and a novel type with an improved structure. From the motor structure, the new motor has higher mechanical robustness. The cogging torque, maximum output torque, core loss and power angle are presented. All studies show that the motor with an improved structure is also potential to apply in low speed high torque drive system.

\section{References}

[1] K.Atallah, S.D.Calverley, "Design, analysis and realization of a High-performance Magnetic Gear,’’ IEE Proc.-Electr. Power Appl., Vol. 151, No. 2, March 2004.pp.135-143

[2] P.O.Rasmussen,T.O.Andersen,F.T.Joergensen,O.Nielsen "'Development of a High Performance Magnetic Gear”,IEEE Industry Applications ,VOL.3, Oct 2003,pp.1696-1702.

[3] W. N. Fu and S. L. Ho, "A Quantitative Comparative Analysis of a Novel Flux-Modulated Permanent-Magnet Motor for Low-Speed Drive”, IEEE Transactions On Magnetics,VOL. 46, NO. 1, JANUARY 2010, pp. 127-134.

[4] L.L.Wang, J.X.Shen,Y.Wang,and K.Wang, “A Novel Magnetic-Geared Outer-Rotor Permanent-Magnet Brushless Motor,” IEEE Power Electronics,Machines and Drives,April 2008,pp.33-36.

[5] W. N. Fu, and S. L. Ho, "A Flux-modulated Low-speed Motor with an Improved Structure and its Performance Analysis Using Finite-element Method", IEEE Electromagnetic Field Computation,May 2010.

[6] Shi-Uk Chung, Ji-Won Kim, Byung-Chul Woo, Do-Kwan Hong, Ji-Young Lee, and Dae-Hyun Koo, "A Novel Design of Modular Three-Phase Permanent Magnet Vernier Machine With Consequent Pole Rotor”, IEEE Transactions On Magnetics,VOL. 47, NO. 10, OCTOBER 2011, pp. 4215-4218. 